\title{
Physicochemical and functional characterization of chitosan from horn snail gastropod Telescopium telescopium
}

\author{
Thangaraj Jebarani Rajathy ${ }^{1 *}$, Muthukumarasamy Srinivasan ${ }^{1}$, Theivasigamani Mohanraj ${ }^{2}$ \\ ${ }^{1}$ Centre of Advanced Study in Marine Biology, Faculty of marine Science, Annamalai University, Chidambaram, India. \\ ${ }^{2}$ Department of PG Zoology, Aditanar College of Arts and Science, Tiruchendur, India.
}

\author{
ARTICLE INFO \\ Received on: 23/08/2020 \\ Accepted on: 21/12/2020 \\ Available online: 05/02/2021 \\ Key words: \\ Biopolymer, biofilm, \\ chitosan, thermogravimetric, \\ Telescopium telescopium.
}

\begin{abstract}
Chitosan is a naturally occurring biopolymer having immense structural possibilities to formulate novel properties and applications especially in the field of biomedical science. In view of the above, the present findings were aimed to develop chitosan from marine gastropod Telescopium telescopium and characterize its structural, chemical, and thermal properties by means of Fourier Transform Infrared Spectroscopy, X-ray Diffraction, Scanning Electron Microscopy and Thermogravimetric analysis. The synthesized chitosan was soluble in $1 \%$ acetic acid with a degree of deacetylation of $74.96 \%$. The yield was estimated as $42 \%$, with ash and moisture content of $1.2 \%$ and $3.9 \%$, respectively, and showed binding capacities of $240 \%$ (WBC) and $280 \%$ (FBC). The synthesized chitosan exhibited good bactericidal effect towards Bacillus subtilis and Vibrio cholerae. The T. telescopium-derived chitosan also proves to be a novel, non-antibiotic agent preventing biofilm formation.
\end{abstract}

\section{INTRODUCTION}

Chitin is a naturally occurring polysaccharide derived from the exoskeleton or cuticle of different invertebrates such as arthropods, mollusks, cnidarians, pogonophores, and cell walls of algae (Kaya et al., 2014). Natural polymers receive greater attention especially in the biomedical field owing to their structural similarities with biological macromolecules that are easily metabolized into non-cytotoxic residues and naturally eliminated. Chitosan which is a deacetylated form of chitin (Azuma et al., 2015) possesses various biological properties like biocompatibility, biodegradability, and nontoxicity that are very advantageous in the biomedical field (Ramasamy and Shanmugam, 2015). Recently, chitosan has attracted considerable significance based on diverse novel applications.

Chitosan has received extensive attention due to its promising applications in the fields of biomedical, food, and chemical industries. The products of chitosan-based biomedical

\footnotetext{
"Corresponding Author

T. Jebarani Rajathy, Centre of Advanced Study in Marine Biology,

Faculty of marine Science, Annamalai University, Chidambaram, India.

E-mail: jebaranirajathy@gmail.com
}

materials include hydrogel membranes, nanofibers, beads, micro and nanoparticles, and scaffolds and sponges (Jayakumar et al., 2010a). It is considered to be an ideal candidate to fabricate polymeric tissue scaffolds due to its high porosity, biodegradability, and structural integrity (Jayakumar et al., 2010b). One among the notable and much explored is its excellent antimicrobial property inhibiting the growth of a wide spectrum of target organisms like bacteria, fungi, and viruses making it beneficial for use in the field of biomedicine (Jayakumar et al., 2011). Microbial growth on the surface of food has been a major source of food spoilage and food-borne infections. However, chitosan possesses unique property that makes it an ideal component for the development of antimicrobial edible films and coating against these pathogens (Costa et al. 2013).

Several studies are focused on synthesizing chitosan from crustaceans (e.g., shrimp, crab, or krill shells); but incredibly limited research on gastropod-derived chitosan being reported till date. Hence an attempt has been made to utilize the shells of Telescopium telescopium to extract chitosan and characterize its physico-chemical, structural, and functional properties through analytical techniques. 


\section{MATERIALS AND METHODS}

\section{Collection of T. telescopium shells}

Telescopium telescopium commonly known as "horn snail" was utilized as a precursor to the synthesis of chitosan. The T. telescopium shells collected from the intertidal area of Vellar estuary $\left(11^{\circ} 29^{\prime} \mathrm{N}, 79^{\circ} 46^{\prime} \mathrm{E}\right)$ were brought to the laboratory and washed thoroughly with distilled water, sun dried and ground into a fine powder.

\section{Extraction of chitosan}

The powdered sample derived from the T. telescopium shell was initially suspended in $5 \% \mathrm{HCl}$ (room temperature) in the ratio of 1:15 $(w / v)$ for 48 hours for demineralization, Followed by deproteinization with $3 \% \mathrm{NaOH}$ at $70^{\circ} \mathrm{C}$ for 48 hours by using a solvent to solid ratio of 15:1 $(\mathrm{v} / \mathrm{w})$. Finally, the sample was washed several times with distilled water to eliminate the excess $\mathrm{NaOH}$ bound to the sample and then oven-dried at $80^{\circ} \mathrm{C}$ for 5 hours. The resultant product thus obtained is chitin which is further deacetylated, for the removal of acetyl group that involves treating the sample with $60 \% \mathrm{NaOH}$ solution having a solid to solvent ratio of 1:15 $(w / v)$. The residue obtained after 84 hours was washed with distilled water to neutrality and rinsed with Millipore water, which was then filtered and oven-dried at $60^{\circ} \mathrm{C}$ for 6 hours to obtain the final product chitosan (Sangwaranatee et al., 2018). For the structural and functional characterization of chitosan a standard or commercial chitosan was compared with the derived chitosan from T. telescopium.

\section{Determination of yield of chitosan}

The yield of chitosan was determined as the weight of the derived chitosan in relation to the weight of the powdered shell sample before treatment, by following the methodology of Nouri et al. (2016).

\section{Physico-chemical properties}

Solubility

The solubility of chitosan was estimated by following the methodology of Mohanasrinivasan et al. (2014); whereby 200 $\mathrm{mg}$ of extracted chitosan was added to $200 \mathrm{ml}$ each of water and $1 \%$ acetic acid solution.

\section{Determination of ash content}

The ash content of chitosan was estimated by heating them in a muffle furnace which has been preheated to $600^{\circ} \mathrm{C}$ for 8 hours. The sample was then cooled in desiccators and weighed to obtain the ash content (Mohan et al., 2019).

\section{Determination of moisture content}

By employing the gravimetric method the moisture content of chitosan was determined (Mohan et al., 2019); wherein the sample was dehydrated in a hot air oven for 2 hours to constant weight and the variation in the weights of wet and oven-dried sample was calculated as $\%$ moisture.

\section{Degree of deactylation}

The degree of deacetylation (DD) of chitosan was estimated using a fourier transform infrared (FTIR) instrument within a frequency range of $4,000-400 \mathrm{~cm}^{-1}$. The equation by Mohanasrinivasan et al. (2014), was used, where the absorbance at A1629.85 and A3450.65 $\mathrm{cm}^{-1}$ indicate absolute heights of absorption bands of amide and hydroxyl groups, respectively.

$\mathrm{DD}=100-\frac{\left(\mathrm{A} 1629.85 \mathrm{~cm}^{-1}-\mathrm{A} 3450.65 \mathrm{~cm}^{-1}\right) \times 100}{1.33}$

where ' 1.33 ' denotes the ratio of A1629.85/A3450.65 for fully $\mathrm{N}$-acetylated chitosan.

\section{Functional and structural analysis}

\section{FTIR spectroscopy}

The chemical structure of chitosan was achieved by using FTIR technique. The absorption spectrum for chitosan was observed in the range of $4,000 \mathrm{~cm}^{-1}$ to $400 \mathrm{~cm}^{-1}$, using the SHIMADZU IRAffinity - 1S FTIR model spectrophotometer.

Scanning electron microscopy (SEM) with energy dispersive analysis of $X$-rays (EDX)

The microstructure and the elemental composition of chitosan were examined using the Scanning Electron Microscope (model: JEOL-JSM IT200) under an accelerated potential of 20.0 $\mathrm{kV}$ at various magnifications.

$X$-ray diffraction (XRD)

The degree of crystallinity of chitosan was detected using the material analyzer diffractometer equipped with $\mathrm{Cu}$ target $\mathrm{X}$-ray tube, a monochromator filtering wave at $40 \mathrm{kV}$ and $30 \mathrm{~mA}$, that results in a diffraction pattern within the 20 range of $5^{\circ}-80^{\circ}$ with a scanning speed of $0.4 \%$ minutes.

\section{Thermogravimetric (TG/DTA)}

The thermal stability of chitosan was evaluated using a Simultaneous Thermal Analyser (NETZSCH-STA 449 F3 JUPITER Instrument, Germany). A known quantity of chitosan sample was heated up to a temperature of $30-600^{\circ} \mathrm{C}$ with a heating range of $20^{\circ} \mathrm{C} /$ minutes under a nitrogen flow of $50 \mathrm{~cm}^{3} /$ minutes.

\section{Determination of $W B C$}

The Water Binding Capacity of chitosan was estimated using a modified method of Cho et al. (1998) wherein $0.5 \mathrm{~g}$ of chitosan was taken in centrifuge tubes, weighed, and to this $10 \mathrm{ml}$ of deionized water was added. The contents were mixed well and set aside in the ambient temperature for 30 minutes with periodic shaking every 10 minutes. It was then centrifuged at 3,200 rpm for 25 minutes; the supernatant was decanted and the tubes were weighed again. The WBC was calculated using the following equation:

$$
\text { WBC }(\%)=[\text { water bound }(\mathrm{g}) / \text { sample weight }(\mathrm{g})] \times 100
$$

\section{Determination FBC}

The Fat Binding Capacity of chitosan was estimated using a modified method of Cho et al. (1998) that involved weighing centrifuge tubes containing $0.5 \mathrm{~g}$ of sample to which $10 \mathrm{ml}$ of coconut oil is added and left at ambient temperature for 30 minutes with periodic shaking every 10 minutes. It was 
then centrifuged at 3,200 rpm for 25 minutes, the supernatant was decanted and the tubes were weighed again. The FBC was calculated using the following equation:

FBC $(\%)=[$ fat bound $(\mathrm{g}) /$ sample weight $(\mathrm{g})] \times 100$.

\section{Microbial studies}

\section{Antibacterial activity}

The antimicrobial activity was carried out following the method described by Khalili et al. (2012), with minor modifications. The antibacterial activity for both the commercial as well as derived chitosan was tested against two pathogenic bacteria such as Bacillus subtilis (gram-positive) and Vibrio cholerae (gram-negative). Sterile disks infused in different concentrations of chitosan were air-dried and placed on agar plates and were incubated at $37^{\circ} \mathrm{C}$ for 24 hours, after which the zones of inhibition were measured (in $\mathrm{mm}$ ).

\section{Biofilm inhibition assay}

The antibiofilm efficiency of commercial as well as extracted chitosan against the Gram-positive B. subtilis was examined following the protocol described by Ishwarya et al. (2018). The bacterial inoculum was added to the culture plate having nine wells, along with a $0.1 \mathrm{mg} / \mathrm{ml}$ concentration of prepared chitosan solution. To ensure better biofilm formation the inoculated plates were incubated for 24 hours at $37^{\circ} \mathrm{C}$. After the incubation period, the media was decanted using a micropipette and the formed biofilm was then fixed with $100 \mu \mathrm{l}$ absolute methanol and further incubated for 15 minutes at $37^{\circ} \mathrm{C}$. After this step, methanol was removed from the wells, and the biofilms were stained with $0.1 \%$ crystal violet and again incubated at room temperature. After 30 minutes the excess stains were washed with distilled water and the plates were left to dry for 5 hours. After drying, each well was treated with $20 \%$ glacial acetic acid solution, and this de-stained solution was evaluated for optical density measurement at $595 \mathrm{~nm}$ using the ELISA (Enzyme - Linked Immunosorbent Assay) reader.

\section{RESULTS AND DISCUSSION}

\section{Yield}

The total yield of chitosan contributed by T. telescopium was $42 \%$ (Table 1) which is comparable to the study by Palpandi et al. (2009), with $31.14 \%$ and $44.29 \%$ from the shell and operculum of gastropod $N$. crepidularia and Majekodunmi et al. (2017) with a chitosan yield of $51.8 \%$ and $43.8 \%$ from Mytilus edulis and Laevicardium attenuatum, respectively.

Table 1. Physico-chemical and functional properties of chitosan from T. telescopium shell.

\begin{tabular}{lc}
\hline Properties & Value \\
\hline Yield & $42 \%$ \\
DD & $74.96 \%$ \\
Ash content & $1.2 \%$ \\
Moisture content & $3.9 \%$ \\
Appearance & White \\
Solubility & $1 \% \mathrm{CH}_{3} \mathrm{COOH}$ \\
\hline
\end{tabular}

\section{Ash and moisture content}

Ash content is one of the vital parameters that affect solubility and viscosity. A high-quality grade of chitosan is said to have ash content less than 1\%, as reported by Hong and Meyers (1995). In the present study, it was recorded as $1.2 \%$ (Table 1) which is comparable to the observation made by Vinusha and Vijaya (2019), with shrimp shell having $1.4 \%$, fish scales with $1.8 \%$ and $1.6 \%$ from Crab shell. The moisture content of the chitosan was observed to be $3.9 \%$ (Table 1) which is in par with Majekodunmi et al. (2017), wherein $3.28 \%$ and $3.84 \%$ of moisture content was observed for M. edulis and L. attenuatum-derived chitosan, respectively. A report by the Korean Food and Drug Administration indicates that the moisture content of any chitosan should be $<10 \%$.

\section{Solubility}

The derived chitosan from the T. telescopium shell was found to be clearly soluble in $1 \%$ acetic acid and partly soluble in water. According to the literature, chitosan has been reported to be soluble in acidic media such as acetic acid, formic acid, l-glutamic acid, lactic acid, and succinic acid (Romanazzi et al., 2009) and feebly soluble in most common solvents, which forms the greatest limitation for scaling up the compound from laboratory to industrial level.

\section{Degree of deacetylation (DD)}

The dDD of chitosan is an important parameter influencing physical, chemical, and biological properties (Kumari et al., 2017). In the present study, DD of derived chitosan was found to be $74.96 \%$ (Table 1) equivalent to the observations made by Mohanasrinivasan et al. (2014), from the shrimp shell waste with a value of $74.82 \%$ and Kumari et al. (2017), that reported $75 \%$, $78 \%$, and $70 \%$ for fish, shrimp, and crab chitosan, respectively. Besides, the results by Majekodunmi et al. (2017) show a DD value of $69.6 \%$ from $M$. edulis and $37.3 \%$ from $L$. attenuatum. The DD greatly influences the solubility, chemical reactivity and biodegradability of the compound and varies depending on the method employed for sample preparation and the types of instruments used for the analysis (Khan, 2002). Similarly, Muñoz et al. (2015) reported DD of $73.6 \%$ from a fungus and stated that the value is based upon the source of chitin derivative, time, temperature, and alkaline concentration used during the process of extraction.

\section{FTIR analysis}

The functional property of chitosan was characterized by FTIR (Fig. 1). The spectrum showed a peak at $873.75 \mathrm{~cm}^{-1}$ that could be attributed to $\mathrm{C}-\mathrm{N}$ stretching. The absorption peak at $1,454.33 \mathrm{~cm}^{-1}$ is due to $\mathrm{C}-\mathrm{H}$ bending of the side chain $-\mathrm{CH}_{2} \mathrm{OH}$, the peak at $1,654.92 \mathrm{~cm}^{-1}$ is a characteristic bending vibration of N-H similar to the observation recorded by Kaya et al. (2014) in the bat guano indicating the formation of chitosan polymer. The band at $3,637.75 \mathrm{~cm}^{-1}$ is characteristic of free $\mathrm{O}-\mathrm{H}$ groups, while that of $1,103.28 \mathrm{~cm}^{-1}$ is attributed to the $\mathrm{C} \mathrm{O} \mathrm{C}$ stretching mode that almost corresponds to the observation by Shanmugam et al. (2016) with $1,106.85 \mathrm{~cm}^{-1}$. A high intensity of peak associated with $\mathrm{N}-\mathrm{H}$ vibration indicates deacetylation of the chitin that shows 
the prevalence of $\mathrm{NH}_{2}$ groups (Majekodunmi et al., 2017). The spectrum is relatively equivalent to that of commercial chitosan and all these are typical absorption peaks of chitosan molecules.

\section{SEM-EDX analysis}

The structural characterization of chitosan was studied by SEM micrograph that shows the difference in the surface morphology between the gastropod derived and commercial

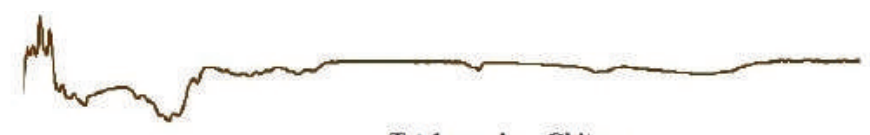

T.telescopium Chitosan

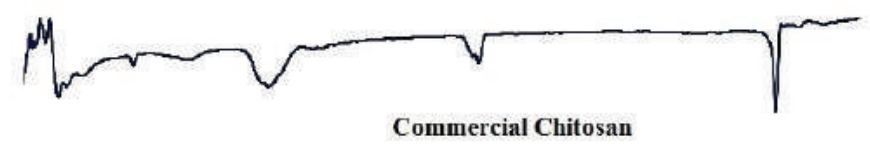

$\begin{array}{cccccccc}400 & 900 & 1400 & 1900 & 2400 & 2900 & 3400 & 3900 \\ & \\ & \text { Wavelength } \text { cm }^{-1} & & \end{array}$

Figure 1. FTIR spectra of T. telescopium chitosan and commercial chitosan. chitosan. For T. telescopium chitosan the micrograph (Fig. 2a) shows a smooth and homogenous surface with clustering of uneven particles that were rod-like and disk-like structures, dispersed as flakes under high magnification, similar to the observation recorded by Masotti (2008). Yen et al. (2009) reported that, at higher magnification, some parts of chitosan exhibited crumbling flakes which is also observed in the present study; whereas for commercial chitosan (Fig. 2b) a non-smooth and non-homogenous surface is observed. The surface morphology of chitosan derived from different sources display different pattern, thus playing a significant role in determining application in various fields (Shanmugam et al., 2016). The elemental composition of the chitosan was studied by EDX that showed the presence of carbon, oxygen, calcium, zinc, iron and magnesium elements.

\section{XRD analysis}

The XRD pattern of chitosan (Fig. 3) exhibited a significant peak at $2 \theta=9.9-10.9^{\circ}$ and sharp crystalline reflections at $20=18-20^{\circ}$ and around $34-35^{\circ}$ which are typical finger prints of semi-crystalline chitosan similar to the XRD pattern derived from the marine crab shell chitosan (Munusamy et al., 2017). Similarly, Yen et al. (2007) found that fungal chitosan displayed two crystalline reflections at $9.7^{\circ}$ and $19.9^{\circ}$; while Harish Prashanth et al. (2002) recorded two major characteristic peaks for shrimp chitosan at $20=9.9-10.7^{\circ}$ and $19.8-20.7^{\circ}$. A study by Yen et al. (2009)
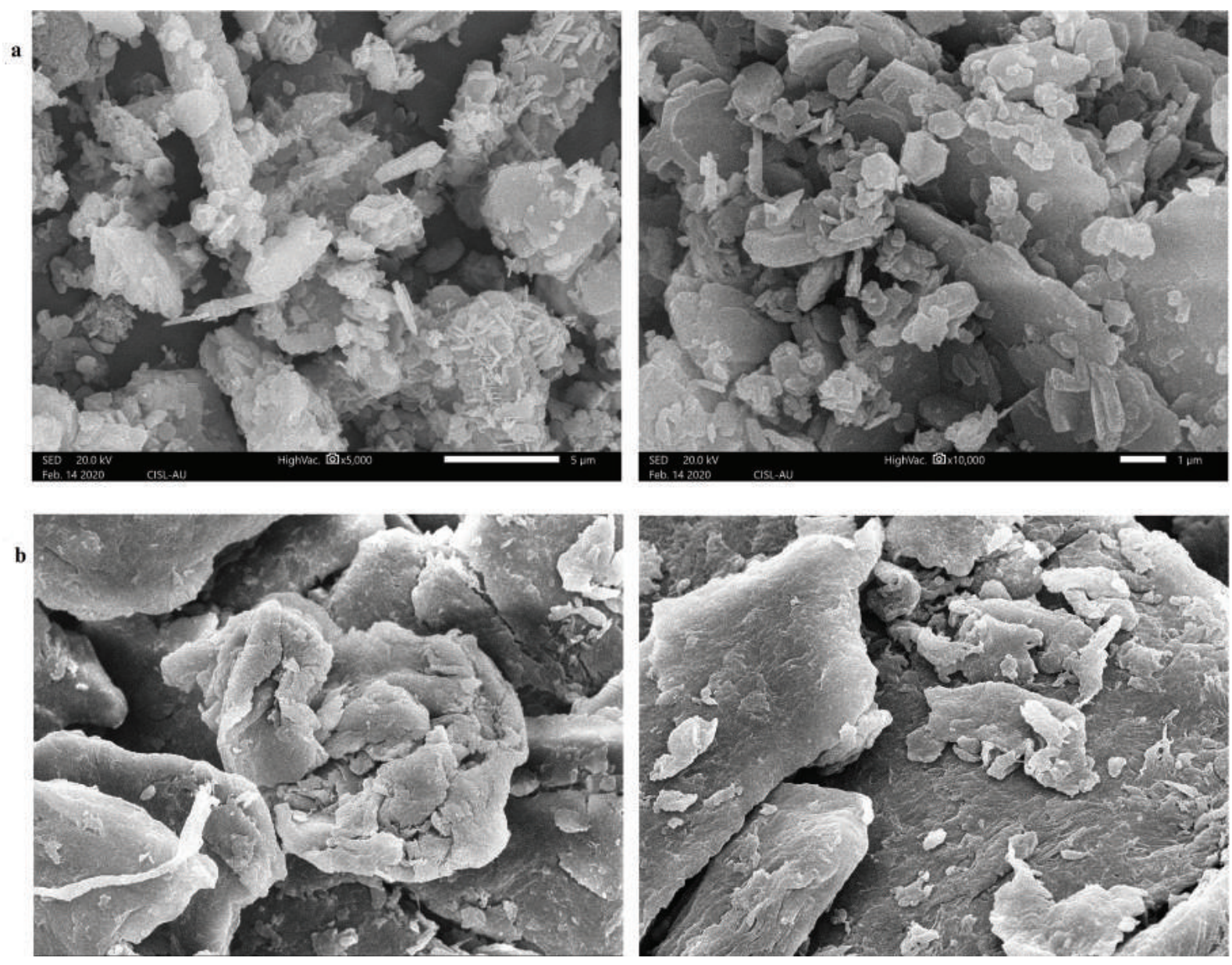

Figure 2. SEM micrograph of (a) T. telescopium chitosan and (b) commercial chitosan. 


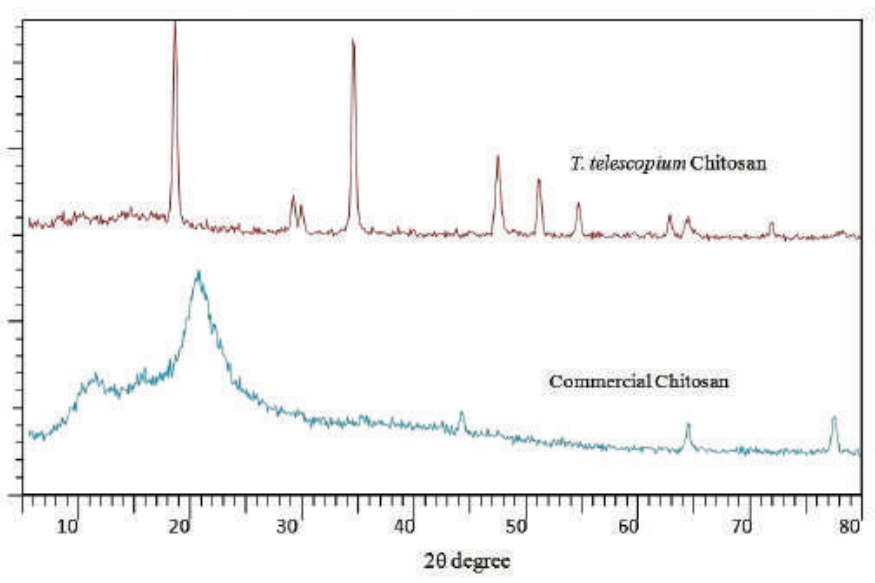

Figure 3. XRD pattern of T. telescopium chitosan and commercial chitosan.

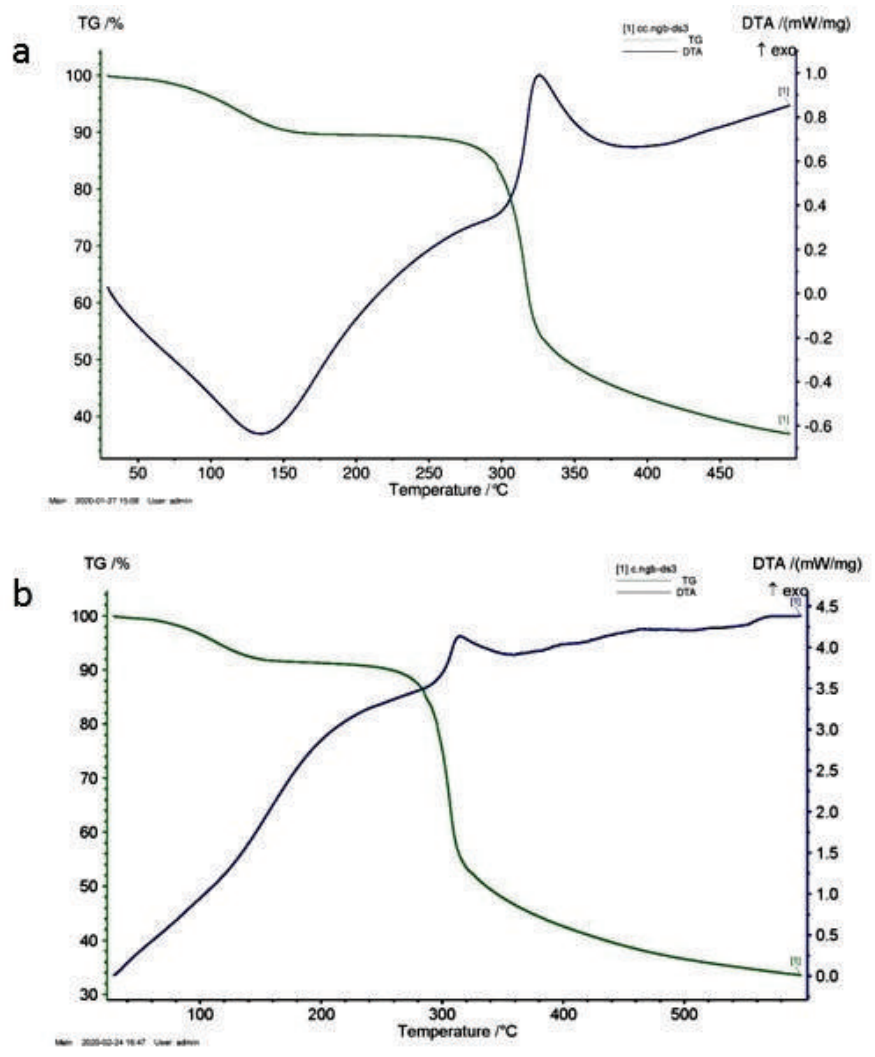

Figure 4. TG/DTA curves for (a) T. telescopium chitosan and (b) commercial chitosan.

reported two characteristic peaks ( $\alpha$ - and $\gamma$-chitosan) with slightly fluctuated diffraction angles, exhibited an equivalent degree of crystallinity with peaks formed at $18-19^{\circ}$ and $34-35^{\circ}$ respectively. The diffraction pattern of commercial and extracted chitosan shows more or less comparable intensities of peaks, which shows the crystalline and amorphous properties of the compound.

\section{TG/DTA}

The TG/DTA curves of the derived chitosan and commercial chitosan recorded in the temperature range of $0^{\circ} \mathrm{C}-600^{\circ} \mathrm{C}$ are shown in Figure 4. The TG curve of chitosan displays two steps of decomposition. The first step of degradation due to release of typical strong hydrogen-bonded water (Zawadzki and Kaczmarck, 2010) was observed at $104^{\circ} \mathrm{C}$ and $113^{\circ} \mathrm{C}$ for derived and commercial chitosan, respectively. Subsequently, the second step, which is the degradation of saccharide structure in the molecule, was recorded as $324^{\circ} \mathrm{C}$ and $313^{\circ} \mathrm{C}$ for derived and commercial chitosan respectively. The maximum thermal degradation was reported as $444^{\circ} \mathrm{C}$ and $438^{\circ} \mathrm{C}$ for the prepared and commercial chitosan, respectively; which shows that extracted chitosan is more stable compared to the commercial chitosan molecule. De Andrade et al. (2012) has reported a maximum decomposition range of $400^{\circ} \mathrm{C}-500^{\circ} \mathrm{C}$ for crab chitosan.

\section{WBC and FBC}

Water and Fat binding capacities of chitosan are functional properties that vary based on the technique followed. The derived chitosan has a WBC of $240 \%$ which is less compared to previous studies by Kumari et al. (2017) with a WBC of $358 \%$ for shrimp shell chitosan. Similarly, No et al. (2000) reported WBC of five commercial chitosans that ranged between $355 \%$ and $611 \%$. Knorr (1982) illustrated that variation in WBC mainly depends upon the source of chitosan, variation in crystallinity, number of salt-forming groups, and residual protein content of chitosan. The above-mentioned parameters could be the reason for the reduced WBC value of the prepared chitosan. The FBC of the prepared chitosan was $280 \%$ which is comparable to the observations made by Kumari et al. (2017) with $246 \%$ from shrimp shells and No et al. (2000) that reported $217 \%-403 \%$ from five commercial chitosans.

\section{Antibacterial activity}

The minimum bactericidal concentration (MBC) of chitosan was studied for two bacterial strains. At 10, 20, and 30 $\mathrm{mg} / \mathrm{ml}$ concentrations of chitosan, a slight effect on the growth of B. subtilis was observed. However, at $40 \mathrm{mg} / \mathrm{ml}$ concentration, the growth of $B$. subtilis was repressed with a $0.2 \mathrm{~cm}$ zone of inhibition for both the synthesized and commercial chitosan; furthermore, at $50 \mathrm{mg} / \mathrm{ml}$ concentration the zone of inhibition was observed at $0.4 \mathrm{~cm}$ for both chitosan compounds. This shows a decrease in the concentration of chitosan may lead to a decrease in the zone of inhibition. For $V$. cholerae a partial zone of inhibition was observed at all concentrations for synthesized chitosan, while commercial chitosan showed $0.6 \mathrm{~cm}$ inhibition at a concentration of $40 \mathrm{mg} / \mathrm{ml}$ and slight zones for the rest of the concentrations. Generally, the microbial inhibitory activity of chitosan is based on its chemical and structural properties (Raafat and Sahl, 2009). The present investigation reveals that synthesized chitosan showed good inhibitory activity similar to the commercial chitosan towards both pathogenic bacterial strains, B. subtilis and $V$. cholerae. Study by Qin et al. (2006) described that chitosan with low-to-medium molecular weight and having a high DD of over $80 \%$ is observed to restrain the development of both grampositive and gram-negative bacteria.

\section{Biofilm inhibition assay}

The effect of chitosan on preventing biofilm formation has been studied by various researchers (Rinaudo, 2006) and is 
now been widely accepted that the biofilm is the predominant mode of bacterial growth that differ substantially in terms of growth rate, gene expression, and structural properties (Donlan and Costerton, 2002). Hence, testing for antimicrobial properties not only against growing bacterial colonies but also against microbial biofilms is mandatory. During the present study only a single concentration of $40 \mathrm{mg} / \mathrm{ml}$ chitosan extract was tested against biofilm formation in all the nine wells for $B$. subtilis; as the $\mathrm{MBC}$ was best observed at this minimal concentration of chitosan. A $32 \%$ and $68 \%$ reduction in biofilm formation against the grampositive bacteria (B. subtilis) was obtained from the derived and commercial chitosan respectively; which is indicative of antibiofilm mode of action (Batoni et al., 2016). Hence the biofilm-preventing activity of the synthesized chitosan also promises to be a simple and practical agent for biofilm control in the fields of food and medical industry.

\section{CONCLUSION}

Recently several health care, biomedical, and pharmaceutical industries are in need of high quality, biocompatible and biodegradable substances like chitosan for addressing many health related issues. Fortunately huge quantities of gastropod shell wastes are available as biowastes around the coastline that could be transformed as a potent source of chitosan. By following this aspect chitosan was synthesized using T. telescopium shell waste which is an abundant raw material along Vellar estuary and screened for its structural and functional properties using Fourier Transform Infrared Spectroscopy, XRD, TG/DTA, and SEM analysis. The good quality yield contributed by $T$. telescopium, a high DD and antimicrobial properties indicate that $T$. telescopium is a potential natural source of chitosan that can perform as a promising ingredient in the research and development of novel biomedical products.

\section{ACKNOWLEDGEMENT}

The authors devote sincere thanks to DST PURSE Phase-II Project for its financial assistance. We are grateful to Dr. S. Ravichandran, Associate Professor and T. Gobinath, Doctorate Research Scholar, CAS in Marine Biology, Annamalai University, for their support rendered during this research work.

\section{AUTHORS CONTRIBUTION}

Concept, Data acquisition, Data analysis / interpretation and Drafting manuscript by Miss. T. Jebarani Rajathy; Designing, Critical revision of manuscript, Statistical analysis, technical or material support by Dr. T. Mohanraj; Investigation and Supervision by Prof.M.Srinivasan

\section{CONFLICT OF INTEREST}

The authors have no conflict of interest to declare.

\section{FUNDING}

DST PURSE Phase-II project.

\section{ETHICAL APPROVALS}

Not applicable.

\section{PUBLISHER'S NOTE}

This journal remains neutral with regard to jurisdictional claims in published institutional affiliation.

\section{REFERENCES}

Azuma K, Izumi R, Osaki T, Ifuku S, Morimoto M, Saimoto H, Minami S, Okamoto Y. Chitin, chitosan, and its derivatives for wound healing: old and new materials. $J$ Funct Biomater, 2015; 6, 104-42; doi:10.3390/jfb6010104.

Batoni G, Maisetta G, Esin S. Antimicrobial peptides and their interaction with biofilms of medically relevant bacteria. Biochim Biophys Acta, 2016; 1858:1044-60.

Cho YI, No HK, Meyers SP. Physicochemical characteristics and functional properties of various commercial chitin and chitosan products. J Agric Food Chem, 1998; 46:3839-43; doi:10.1021/jf971047f

Costa EM, Silva S, Tavaria FK, Pintado MM. Study of the effects of chitosan upon streptococcus mutans adherence and biofilm formation. Anaerobe, 2013; 20:27-31; doi:10.1016/j.anaerobe.2013.02.002

De Andrade SMB, Ladchumananandasivam R, da Rocha BG, Belarmino DD, Galvão AO. The use of exoskeletons of shrimp and crab for the extraction of chitosan and production of nanomembrane. Mater Sci Appl, 2012; 03:495-508; doi:10.4236/msa.2012.37070

Donlan RM, Costerton JW. Biofilms: survival mechanisms of clinically relevant microorganisms. Clin Microbiol Rev, 2002; 15:167-93.

Harish Prashanth KV, Kittur FS, Tharanathan RN. Solid state structure of chitosan prepared under different $\mathrm{N}$-deacetylating conditions, Carbohydr Polym, 2002; 50:27-33; doi:10.1016/S0144-8617(01)00371-X

Ishwarya R, Vaseeharan B, Kalyani S, Banumathi B, Govindarajan M, Alharbid NS, Kadaikunnand S, Al-anbrd MN, Khaledd JM, Benellie G. Green synthesis of zinc oxide nanoparticles using Ulva lactuca seaweed extract and evaluation of their photocatalytic, antibiofilm and insecticidal activity. J Photochem Photobiol B, 2018; 178:249-58, doi:10.1016/j.jphotobiol.2017.11.006

Jayakumar R, Nair SV, Furuike T, Tamura H. Perspectives of chitin and chitosan nanofibrous scaffolds in tissue engineering, tissue engineering, Daniel Eberli. IntechOpen, London, UK, pp 205-25, 2010b.

Jayakumar R, Prabaharan M, Nair SV, Tamura H. Novel chitin and chitosan nanofibers in biomedical applications. Biotechnol Adv, 2010a; 28:142-50; doi:10.1016/j.biotechadv.2009.11.001

Jayakumar R, Prabaharan M, Sudheesh Kumar PT, Nair SV, Tamura H. Biomaterials based on chitin and chitosan in wound dressing applications. Biotechnol Adv, 2011; 29:322-37; doi:10.1016/j. biotechadv.2011.01.005

Kaya M, Seyyar O, Baran T, Turkes T. Bat guano as new and attractive chitin and chitosan source. Front Zool, 2014; 11:1-10; doi:10.1186/s12983-014-0059-8

Khalili H, Soltani R, Negahban S, Abdollahi A, Gholami K. Reliability of disk diffusion test results for the antimicrobial susceptibility testing of nosocomial gram-positive microorganisms: is e-test method better? Iran J Pharm Res, 2012; 11:559-63; doi:10.22037/ijpr.2012.1094

Khan WM, Prithiviraj B, Smith DL. Effect of foliar application of chitin and chitosan oligosaccharides on photosynthesis of maize and soybean. Photosynthetica, 2002; 40:621-4; doi:10.1023/A:1024320606812

Knorr D. Functional properties of chitin and chitosan. J Food Sci, 1982; 47:593-5; doi:10.1111/j.1365-2621.1982.tb10131.x

Kumari S, Kumar Annamareddy SH, Abanti S, Kumar Rath P. Physicochemical properties and characterization of chitosan synthesized from fish scales, crab and shrimp shells. Int J Biol Macromol, 2017; 104:1697-705; doi:10.1016/j.ijbiomac.2017.04.119

Majekodunmi SO, Olorunsola EO, Uzoaganobi CC. Comparative physicochemical characterization of chitosan from shells of two bivalved mollusks from two different continents. Am J Polym Sci, 2017; 7:15-22; doi:10.5923/j.ajps.20170701.03

Masotti A, Bordi F, Ortaggi G, Marino F, Palocci C. A novel method to obtain chitosan/DNA nanospheres and a study of their release properties. Nanotechnology, 2008; 19(5):055302; doi:10.1088/09574484/19/05/055302

Mohan CO, Gunasekaran S, Ravishankar CN. Chitosan-capped gold nanoparticles for indicating temperature abuse in frozen stored products. NPJ Sci Food, 2019; 3:1-6; doi:10.1038/s41538-019-0034-z 
Mohanasrinivasan V, Mishra M, Paliwal JS, Singh SK, Selvarajan E, Suganthi V, Subathra Devi C. Studies on heavy metal removal efficiency and antibacterial activity of chitosan prepared from shrimp shell waste. 3 Biotech, 2014; 4:167-75; doi:10.1007/s13205-013-0140-6

Muñoz G, Valencia C, Valderruten N, Ruiz-Durántez E, Zuluaga F. Extraction of chitosan from Aspergillus niger mycelium and synthesis of hydrogels for controlled release of betahistine. React Funct Polym, 2015; 91:1-10; doi:10.1016/j.reactfunctpolym.2015.03.008

Munusamy MA, Subbiah SK, Rajan M. Reducing indicator organism E. coli in drinking water using chitosan nano coated pot system: an inexpensive technique. Prog Biosci Bioeng, 2017; 1(1): 36-43; doi:10.29269/pbb2017.v1i1.4.13

NoHK, LeeKS, Meyers SP. Correlation between physicochemical characteristics and binding capacities of chitosan products. J Food Sci, 2000; 65:1134-7; doi:10.1111/j.1365-2621.2000.tb10252.x

Hong K, Meyers SP. Preparation and characterization of chitin and chitosan- a review. J Aquat Food Prod Technol, 1995; 4:27-52; doi:10.1300/J030v04n02_03

Nouri M, Khodaiyan F, Razavi SH, Mousavi M. Improvement of chitosan production from persian gulf shrimp waste by response surface methodology. Food Hydrocoll, 2016; 59:50-8; doi:10.1016/j. foodhyd.2015.08.027

Palpandi C, Shanmugam V, Shanmugam A. Extraction of chitin and chitosan from shell and operculum of mangrove gastropod Nerita (Dostia) crepidularia lamarck. Int J Med Med Sci, 2009; 1:198-205.

Qin C, Li H, Xiao Q, Liu Y, Zhu J, Du Y. Water-solubility of chitosan and its antimicrobial activity. Carbohydr Polym, 2006; 63:367-74; doi:10.1016/j.carbpol.2005.09.023

Raafat D, Sahl HG. Chitosan and its antimicrobial potential - a critical literature survey. Microb Biotechnol, 2009; 2:186-201; doi:10.1111/ j.1751-7915.2008.00080.x

Ramasamy P, Shanmugam A. Characterization and wound healing property of collagenchitosan film from Sepia kobiensis (Hoyle, 1885). Int J Biol Macromol, 2015; 74:93-102; doi:10.1016/j.ijbiomac.2014.11.034
Rinaudo M. Chitin and chitosan: properties and applications. Prog Polym Sci, 2006; 31:603-32; doi:10.1016/j.progpolymsci.2006.06.001

Romanazzi G, Gabler FM, Margosan D, MacKey BE, Smilanick JL. Effect of chitosan dissolved in different acids on its ability to control postharvest gray mold of table grape. Phytopathology, 2009; 99:1028-36; doi:10.1094/PHYTO-99-9-1028

Sangwaranatee NW, Teanchai K, Kongsriprapan S, Siriprom W. Characterization and analyzation of chitosan powder from Perna Viridis shell. Mater Today, 2018; 5:13922-5; doi:10.1016/j.matpr.2018.02.041

Shanmugam A, Kathiresan K, Nayak L. Preparation, characterization and antibacterial activity of chitosan and phosphorylated chitosan from cuttlebone of Sepia kobiensis (Hoyle, 1885). Biotechnol Rep, 2016; 9:25-30; doi:10.1016/j.btre.2015.10.007

Vinusha B, Vijaya C. Extraction and characterization of chitosan from shrimp shell waste in sabah. Trans Sci Technol, 2019; 3:2217-20.

Yen MT, Tseng YH, Li RC, Mau JL. Antioxidant properties of fungal chitosan from shiitake stipes, LWT. Food Sci Technol, 2007; 40:255-61; doi:10.1016/j.lwt.2005.08.006

Yen MT, Yang JH, Mau JL. Physicochemical characterization of chitin and chitosan from crab shells. Carbohydr Polym, 2009; 75:15-21; doi:10.1016/j.carbpol.2008.06.006

Zawadzki J, Kaczmarek H. Thermal treatment of chitosan in various conditions. Carbohydr Polym, 2010; 80:394-400; doi:10.1016/j. carbpol.2009.11.037

How to cite this article:

Jebarani Rajathy T, Srinivasan M, Mohanraj T. Physicochemical and functional characterization of chitosan from horn snail gastropod Telescopium telescopium. J Appl Pharm Sci, 2021; 11(02):052-058. 